Published in final edited form as:

Chem Res Toxicol. 2016 August 15; 29(8): 1293-1297. doi:10.1021/acs.chemrestox.6b00121.

\title{
Chronic treatment with isoniazid causes protoporphyrin IX accumulation in mouse liver
}

\author{
Madhav Sachar ${ }^{\dagger}$, Feng Li ${ }^{\ddagger}$, Ke Liu ${ }^{\dagger}$, Pengcheng Wang ${ }^{\dagger}$, Jie Lu ${ }^{\dagger}$, and Xiaochao $\mathrm{Ma}^{\dagger},{ }^{\star}$ \\ tCenter for Pharmacogenetics, Department of Pharmaceutical Sciences, School of Pharmacy, \\ University of Pittsburgh, Pittsburgh, PA \\ ‡Department of Molecular and Cellular Biology, Baylor College of Medicine; Houston, TX
}

\begin{abstract}
Isoniazid (INH) can cause hepatotoxicity. In addition, INH is contraindicated in patients suffering from porphyrias. Our metabolomic analysis revealed that chronic treatment with INH in mice causes a hepatic accumulation of protoporphyrin IX (PPIX). PPIX is an intermediate in the heme biosynthesis pathway and it is also known as a hepatotoxin. We further found that INH induces delta-aminolevulinate synthase 1 (ALAS1), the rate-limiting enzyme in heme biosynthesis. We also found that INH downregulates ferrochelatase (FECH), the enzyme that converts PPIX to heme. In summary, this study illustrated that chronic treatment with INH causes PPIX accumulation in mouse liver in part through ALAS1 induction and FECH downregulation. This study also highlights that drugs can disrupt the metabolic pathways of endobiotics and increase the risk of liver damage.
\end{abstract}

\section{Graphical Abstract}

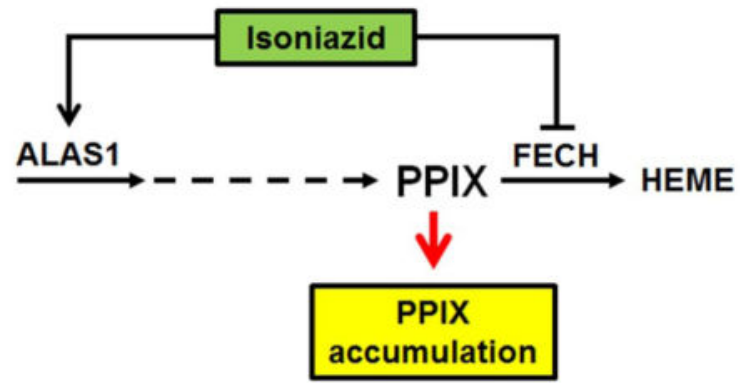

\footnotetext{
Keywords

Isoniazid; protoporphyrin IX; delta-aminolevulinate synthase 1; ferrochelatase; hepatotoxicity

*Corresponding author: School of Pharmacy, University of Pittsburgh, Pittsburgh, PA 15261. Tel. (412) 648-9448, mxiaocha@ pitt.edu. The authors declare to have no conflict of interest.

Supporting information

Table S1: water consumption and dosage of INH. Figure S1-S5: validation of methods for western blotting of FECH and ALAS1; evaluation of liver damage in mice treated with INH; hemoglobin in the liver of mice treated with INH; effect of INH and its metabolites on FECH activity; and effect of INH on FECH mRNA expression in mouse liver. These supporting data are available free of charge via the internet at http://pubs.acs.org/.
} 


\section{Introduction}

Tuberculosis (TB) is one of the most prevalent infectious diseases in the world. ${ }^{1}$ In 2014 alone, approximately 9.6 million people contracted TB and 1.5 million people died because of TB. ${ }^{1}$ Isoniazid (INH) is usually used together with other first-line drugs for TB treatment. INH can also be used alone for TB prevention. However, INH can cause hepatotoxicity and even liver failure. ${ }^{2,3}$ A previous study showed that co-treatment with INH and rifampicin caused the hepatic accumulation of protoporphyrin IX (PPIX) and liver injury in the pregnane $\mathrm{X}$ receptor (PXR)-humanized mice. ${ }^{4}$ PPIX is an intermediate in the heme biosynthesis pathway and its accumulation is the primary cause of liver injury in patients suffering from erythropoietic protoporphyria. ${ }^{5-7}$ Rifampicin is a human PXR ligand that induces delta-aminolevulinate synthase 1 (ALAS1), the rate-limiting enzyme regulating heme and porphyrin biosynthesis. ${ }^{8}$ However, the role of INH in PPIX accumulation caused by INH and rifampicin co-therapy remains unknown.

INH has been found to potentiate griseofulvin-induced hepatic porphyria. ${ }^{9}$ In addition, INH is used with extreme caution in patients with porphyrias, a group of disorders in the heme biosynthesis pathway. ${ }^{10}$ These data suggest that INH itself may cause porphyric abnormalities. Here we used an untargeted metabolomics approach to investigate the effect of INH on liver metabolome. We found that chronic treatment with INH causes a hepatic accumulation of PPIX in both dose-dependent and time-dependent manners. We also found that INH-mediated PPIX accumulation in the liver is caused by induction of ALAS1 and downregulation of ferrochelatase (FECH), the enzymes regulating PPIX biosynthesis and metabolism, respectively.

\section{Material and Methods}

\section{Chemicals and reagents}

INH, PPIX, heme, delta-aminolevulinate acid (ALA), glycine, succinyl-CoA and $N$-methyl PPIX were purchased from Sigma-Aldrich (St. Louis, MO). All solvents for metabolite analysis were of the highest grade commercially available.

\section{Animals and treatment}

All animal experiments were performed in accordance with the Institutional Animal Care and Use Committee. FVB/NJ mice (male, six weeks old) were purchased from the Jackson Laboratory (Bar Harbor, ME) and were maintained in $12 \mathrm{hr}$ light/dark cycle. For the timedependent effect of INH on the liver, mice were provided with drinking water supplemented with $400 \mathrm{mg} / \mathrm{L}$ INH for $0,3,7,14$ and 28 days. For the dose-dependent effect of INH on the liver, mice were treated with $0,100,200$ and $400 \mathrm{mg} / \mathrm{L}$ INH in drinking water for 14 days. A slight decrease in water consumption was observed in 200 and $400 \mathrm{mg} / \mathrm{L} \mathrm{INH}$ groups during INH treatment (Table S1). After INH treatment, all mice were sacrificed. Liver, red blood cells (RBCs), serum, and bone marrow cells (BMCs) were collected for further analysis. 


\section{Biochemical and pathological analysis}

For biochemical analysis, the serum alanine transaminase (ALT) level was measured using the standard protocol (Abcam, Cambridge, MA). For pathological analysis, liver tissue was fixed in $4 \%$ formaldehyde phosphate buffer. The fixed liver tissue was subjected to dehydration in serial alcohol and xylene concentration and finally embedded in paraffin. Four-micrometer serial sections were cut and stained with hematoxylin and eosin (H\&E).

\section{Metabolomic analysis}

Liver metabolome was explored using a previously described method. ${ }^{11}$ Briefly, $100 \mathrm{mg}$ of liver samples were homogenized in $400 \mu \mathrm{l}$ water. In $100 \mu \mathrm{l}$ of liver homogenate, $200 \mu \mathrm{l}$ methanol was added and then vortexed two times for $1 \mathrm{~min}$. The mixture was centrifuged at $15,000 \mathrm{~g}$ for $10 \mathrm{~min}$ and the supernatant was centrifuged again at 15,000 $\mathrm{g}$ for $10 \mathrm{~min}$. The supernatant was collected and injected into ultra-performance liquid chromatography (UPLC)-quadrupole time-of-flight mass spectrometry (QTOFMS) for metabolite analysis. A Waters Acquity BEH C18 column $(2.1 \times 100 \mathrm{~mm}, 1.7 \mu \mathrm{m}$; Waters, Milford, MA) was used for metabolite separation. The column temperature was maintained at $50{ }^{\circ} \mathrm{C}$. QTOFMS (Waters Corp, Milford, MA) was operated in positive mode with electrospray ionization. The source and desolvation temperatures were set at $150{ }^{\circ} \mathrm{C}$ and $500{ }^{\circ} \mathrm{C}$, respectively. Nitrogen was applied as cone and desolvation gas. Capillary and cone voltages were set at $0.8 \mathrm{kV}$ and $40 \mathrm{~V}$. QTOFMS was calibrated with sodium formate and monitored by the intermittent injection of lockspray leucine enkephalin. MS data were acquired over a range of 50-1000 Da at a rate of 0.1 scans/second in centroid format. For data analysis, MassLynx 4.1 was used to acquire mass spectra in centroid format. A multivariate data matrix containing sample identity, ion identity $(\mathrm{m} / \mathrm{z}$ and retention time) and ion abundance was generated and was exported into SIMCA-P+ (Version 13, Umetrics, Kinnelon, NJ). The data were further analyzed using principal component analysis (PCA) and orthogonal partial least-squares discriminant analysis (OPLS-DA).

\section{PPIX quantification}

To extract PPIX from RBCs and BMCs, $10^{7}$ cells were sonicated in $100 \mu \mathrm{l}$ of methanol and water ( $v / v, 4: 1)$. To extract PPIX from serum, $80 \mu \mathrm{l}$ methanol was added to $20 \mu \mathrm{l}$ of serum and vortexed twice. The mixture was vortexed and then centrifuged at 15,000 $\mathrm{g}$ for $10 \mathrm{~min}$. Analysis of PPIX was conducted using UPLC-QTOFMS. The data were acquired using Masslynx 4.1 and quantified by QuanLynx.

\section{FECH activity assay}

FECH activity assay was performed using previously described methods. ${ }^{12-14}$ In brief, $5 \mu \mathrm{g}$ of liver mitochondria was added to $100 \mu \mathrm{l}$ of $50 \mu \mathrm{M}$ PPIX (100 mM Tris-HCl, $\mathrm{pH} 8.0,1 \mathrm{mM}$ DTT, $0.1 \%$ (v/v) Triton X-100). To initiate reaction, an equal volume of $100 \mu \mathrm{M}$ iron citrate prepared in $100 \mathrm{mM}$ Tris- $\mathrm{HCl}(\mathrm{pH} 8.0)$ was added. Incubations were carried out at $37^{\circ} \mathrm{C}$ for $1 \mathrm{hr}$ in the dark. Twice the volume of methanol was added to stop the reaction. The mixture was vortexed for $1 \mathrm{~min}$ and then centrifuged at 15,000 $\mathrm{g}$ for $10 \mathrm{~min}$. The supernatant was collected for analysis of heme using UPLC-QTOFMS. 


\section{ALAS activity assay}

ALAS activity was analyzed using the mitochondria isolated from the liver of mice treated with INH. The assay was conducted using a previous protocol with slight modification. ${ }^{15}$ Briefly, $50 \mu \mathrm{g}$ of mitochondria was incubated in $100 \mu \mathrm{l}$ glycine buffer $(35 \mathrm{mM}$ Tris-HCl, $\mathrm{pH}$ 7.4, $30 \mathrm{mM} \mathrm{Na} 2 \mathrm{HPO}_{4}, 8 \mathrm{mM} \mathrm{MgCl}_{2}, 0.2 \mathrm{mM}$ pyridoxal phosphate, $25 \mu \mathrm{M}$ succinylacetone, $5 \mathrm{mM}$ EDTA and $150 \mathrm{mM}$ glycine) for $1 \mathrm{~h}$ at $37^{\circ} \mathrm{C}$. The product of ALAS was analyzed using UPLC-QTOFMS as described previously 16

\section{Western blotting}

Liver homogenates were used for analysis of ALAS1 and FECH proteins. Briefly, $50 \mu \mathrm{g}$ of proteins per sample were resolved using 10\% SDS-polyacrylamide gels and transferred to an Immobilon-P membrane (Millipore, Bedford, MA). The loading amount of each protein was determined based on the detectable and linear range of ALAS1 and FECH, respectively (Figure S1). The membrane was incubated with anti-ALAS1 (1:5000, Abcam, ab84962) and anti-FECH (1:1000, Santa Cruz, sc-377377) antibodies, respectively. Subsequently, the membrane was incubated with DyLight 800 4X PEG conjugated goat anti-rabbit (1:10,000, Thermo Scientific, SA5-35571) and DyLight 680 conjugated goat anti-mouse (1:10,000, Thermo Scientific, 35519) secondary antibodies. Protein was visualized using the Odyssey infrared imaging system (LICOR, Lincoln, NE) and was quantified using the corresponding software. K-562 whole cell lysate (Santa Cruz, sc-2203) was used as a positive control of both ALAS1 and FECH. GAPDH was used as loading control. This method has been verified by checking the linear range, positive control, and MW markers (Figure S1).

\section{Real-time PCR}

RNA in the liver was isolated using Trizol®. cDNA was reverse transcribed from total RNA using Superscript3 (Invitrogen, Carlsbad, CA). Real-time quantification of mRNA was conducted using the QuantStudio ${ }^{\mathrm{TM}} 6$ Flex real-time PCR system (Applied Biosystems, Foster City, CA) and the SYBR Green PCR master mix. The target mRNA expression was normalized against cyclophilin expression.

\section{Statistical analysis}

All the data were expressed as means \pm SD. Statistical significance between groups was determined by two-tailed Student's t-test or one-way ANOVA. A P value less than 0.05 was considered as statistically significant.

\section{Results}

\section{Effect of INH on PPIX homeostasis in the liver}

Chronic treatment with INH did not cause significant liver damage in mice (Figure S2). However, liver metabolome was dramatically altered after INH treatment. The PCA analysis clearly separated the untreated group from the INH-treated groups (Figure 1A). The S-plot generated from OPLS-DA showed the ion contribution to the group separation of the untreated and treated groups (Figure 1B). The number 1 ranking ion was identified as PPIX (Figures 1B, 2A and 2B). The structure of PPIX was confirmed by comparing extracted ion 
chromatograph and the MS/MS spectra with the standard PPIX (Figure 2A and 2B). We further confirmed that INH-mediated PPIX accumulation in the liver is time-dependent (Figure 2C) and dose-dependent (Figure 2D). These data suggest that INH disturbs PPIX synthesis and/or metabolism.

\section{Effect of INH on PPIX levels in BMCs, serum and RBCs}

Because bone marrow is the major resource of PPIX production, ${ }^{17}$ we next investigated the effect of INH on PPIX levels in BMCs, serum and RBCs. We find that treatment with INH does not alter PPIX levels in BMCs, serum or RBCs (Figure 3), indicating that INH has no effect on PPIX synthesis and/or metabolism in the bone marrow. In addition, we excluded the possibility of INH-mediated erythrocytes congestion in the liver by analyzing liver histology (Figure S2) and hemoglobin (Figure S3).

\section{Effect of INH on FECH expression and function in the liver}

To determine the mechanism of PPIX accumulation in the liver, we investigated the effect of INH and its major metabolites on the function of FECH, the enzyme that converts PPIX into heme. ${ }^{17}$ We found that INH and its major metabolites have no inhibitory effect on FECH activity (Figure S4); suggesting that INH-mediated PPIX accumulation in the liver is not due to the direct inhibition of INH or its metabolites on FECH. We further examined the effect of INH on FECH expression in the liver. We found that INH has no effect on the mRNA expression of FECH in mouse liver (Figure S5). Interestingly, treatment of INH decreased the level of FECH protein, which is time-dependent (Figure 4A and 4B) and dose-dependent (Figure 4C and 4D).

\section{Effect of INH on ALAS1 expression and function in the liver}

ALAS1 is the rate-limiting enzyme in hepatic PPIX synthesis. ${ }^{5,17}$ We found that treatment with INH has no effect on mRNA expression of ALAS1 (Figure 5A and 5B). However, the levels of ALAS1 protein were significantly increased after INH treatment in both timedependent (Figure 5C and 5D) and dose-dependent (Figure 5E and 5F) manners. Furthermore, treatment with INH increased ALAS1 activity in mouse liver (Figure 5G).

\section{Discussion}

In the current study, we explored the effect of INH on mouse liver metabolome using untargeted metabolomics. We found that INH causes PPIX accumulation in the liver through ALAS1 induction and FECH downregulation. This discovery explains why INH potentiates drug-induced hepatic porphyria, such as rifampicin and griseofulvin. ${ }^{4,9}$ In addition, this study provides a mechanistic understanding of contraindication of INH in patients with porphyrias. ${ }^{10}$ Furthermore, this project provides a novel insight into the mechanism of INHinduced liver injury.

PPIX is mainly produced in the bone marrow and secondly in the liver. ${ }^{5,17}$ PPIX produced in the bone marrow is transported to serum through RBCs and then up taken by hepatocytes. ${ }^{7}$ Therefore, we first examined the effect of INH on PPIX levels in bone marrow, RBCs, and serum. We found that treatment with INH has no significant effect on 
PPIX levels in BMCs, RBCs and serum, suggesting INH-mediated PPIX accumulation in the liver is not through the bone marrow. We next investigated the effect of INH on ALAS1 and FECH, the enzymes that are involved in PPIX synthesis and metabolism, respectively. ${ }^{18-20}$ We found that INH and its metabolites have no inhibitory effect on FECH activity, suggesting that INH-mediated PPIX accumulation in the liver is not due to the direct inhibition of FECH. Interestingly, INH significantly decreases FECH protein level without affecting FECH mRNA level in the liver. The mechanism of INH-mediated downregulating of FECH protein remains unclear. We also found that INH had no significant effect on mRNA expression of ALAS1 in the liver but the protein expression of ALAS1 was significantly induced after INH treatment. This is similar to INH-mediated upregulation of CYP2E1, in which INH increases CYP2E1 expression at protein level but not at mRNA level. $^{21-23}$ These data suggest that INH stabilizes ALAS1 protein and increases PPIX production. Further studies are needed to determine the mechanisms by which INH regulates the protein expressions of ALAS1 and FECH.

Hepatic accumulation of PPIX causes liver injury. ${ }^{5-7}$ Accumulation of PPIX in the liver is associated with increased protein oxidation, decreased proteasome activity, and disruption of mitochondrial function. ${ }^{5,} 24$ In addition, PPIX inhibits cytochrome P450 in liver, which can suppress drug elimination and potentially increase drug toxicity. ${ }^{25}$ Furthermore, PPIX is mainly excreted through the biliary system. Excessive PPIX in bile can cause bile duct blockage and cholestatic liver injury. ${ }^{26}$ Although INH causes PPIX accumulation in the liver, we did not observe severe liver damage. We expect that co-factors that induce ALAS1 will potentiate INH-mediated liver injury. This is supported by the facts that many ALAS1 inducers can potentiate INH hepatotoxicity. ${ }^{4}, 27$ These data suggest that INH can disrupt the metabolic pathway of PPIX and increase the risk of liver damage. Moreover, INH may also disrupt the metabolic pathways of other endobiotics and lead to liver damage.

In summary, this study found that INH causes PPIX accumulation in the liver in part through ALAS1 induction and FECH downregulation. This study also highlights that drugs can interact with metabolic pathways of endobiotics and increase the risk of hepatotoxicity.

\section{Supplementary Material}

Refer to Web version on PubMed Central for supplementary material.

\section{Acknowledgments}

Funding

This work was supported in part by the National Institute of Diabetes and Digestive and Kidney Diseases [DK090305].

\section{Abbreviations}

INH

PPIX

ALAS1 isoniazid

protoporphyrin IX

delta-aminolevulinate synthase 1 
FECH ferrochelatase

UPLC-QTOFMS

ultraperformance liquid chromatography coupled to quadrupole time-of-flight mass spectrometry

PCA

OPLS-DA

RBCs

BMCs principal component analysis

orthogonal partial least-squares discriminant analysis

red blood cells

bone marrow cells

\section{References}

1. World Health Organisation. Global tuberculosis report. 2015.

2. Centers for Disease Control and Prevention. Severe isoniazid-associated liver injuries among persons being treated for latent tuberculosis infection - United States, 2004-2008. MMWR Morb Mortal Wkly Rep. 2010; 59:224-229. [PubMed: 20203555]

3. Mitchell JR, Zimmerman HJ, Ishak KG, Thorgeirsson UP, Timbrell JA, Snodgrass WR, Nelson SD. Isoniazid liver injury: clinical spectrum, pathology, and probable pathogenesis. Ann Intern Med. 1976; 84:181-192. [PubMed: 766682]

4. Li F, Lu J, Cheng J, Wang L, Matsubara T, Csanaky IL, Klaassen CD, Gonzalez FJ, Ma X. Human PXR modulates hepatotoxicity associated with rifampicin and isoniazid co-therapy. Nat Med. 2013; 19:418-420. [PubMed: 23475203]

5. Sachar M, Anderson KE, Ma X. Protoporphyrin IX: the Good, the Bad, and the Ugly. J Pharmacol Exp Ther. 2016; 356:267-275. [PubMed: 26588930]

6. Casanova-Gonzalez MJ, Trapero-Marugan M, Jones EA, Moreno-Otero R. Liver disease and erythropoietic protoporphyria: a concise review. World J Gastroenterol. 2010; 16:4526-4531. [PubMed: 20857522]

7. Anstey AV, Hift RJ. Liver disease in erythropoietic protoporphyria: insights and implications for management. Gut. 2007; 56:1009-1018. [PubMed: 17360790]

8. Podvinec M, Handschin C, Looser R, Meyer UA. Identification of the xenosensors regulating human 5-aminolevulinate synthase. Proc Natl Acad Sci U,S,A. 2004; 101:9127-9132. [PubMed: 15178759]

9. Watanabe M. The synergistic effect of isonicotinic acid hydrazide (INH) and griseofulvin (GF) on porphyrin metabolism. J Dermatol. 1991; 18:39-42. [PubMed: 2050906]

10. America Porphyria Foundation. Porphyria Drug Safety Database. 2016.

11. Liu K, Yan J, Sachar M, Zhang X, Guan M, Xie W, Ma X. A metabolomic perspective of griseofulvin-induced liver injury in mice. Biochem Pharmacol. 2015; 98:493-501. [PubMed: 26343413]

12. Taketani S. Measurement of ferrochelatase activity. Curr Protoc Toxicol. 2001; Chapter 8(Unit 8): 7.

13. Rossi E, Costin KA, Garcia-Webb P. Ferrochelatase activity in human lymphocytes, as quantified by a new high-performance liquid-chromatographic method. Clin Chem. 1988; 34:2481-2485. [PubMed: 3197287]

14. Li FM, Lim CK, Peters TJ. An HPLC assay for rat liver ferrochelatase activity. Biomed Chromatogr. 1987; 2:164-168. [PubMed: 3507230]

15. Sinclair PR, Gorman N, Cornell NW. Measurement of ALA synthase activity. Curr Protoc Toxicol. 2001; Chapter 8(Unit 8):2.

16. Alsarra IA, Yassin AE, Abdel-Hamid M, Alanazi FK, Aljuffali IA. Direct UPLC-MS-MS validated method for the quantification of 5-aminolevulinic acid: application to in-vitro assessment of colonic-targeted oral tablets. J Chromatogr Sci. 2011; 49:428-433. [PubMed: 21682991] 
17. Ajioka RS, Phillips JD, Kushner JP. Biosynthesis of heme in mammals. Biochim Biophys Acta. 2006; 1763:723-736. [PubMed: 16839620]

18. Brady AM, Lock EA. Inhibition of ferrochelatase and accumulation of porphyrins in mouse hepatocyte cultures exposed to porphyrinogenic chemicals. Arch Toxicol. 1992; 66:175-181. [PubMed: 1497480]

19. Teng L, Nakada M, Zhao SG, Endo Y, Furuyama N, Nambu E, Pyko IV, Hayashi Y, Hamada JI. Silencing of ferrochelatase enhances 5-aminolevulinic acid-based fluorescence and photodynamic therapy efficacy. Br J Cancer. 2011; 104:798-807. [PubMed: 21304523]

20. Kemmner W, Wan K, Ruttinger S, Ebert B, Macdonald R, Klamm U, Moesta KT. Silencing of human ferrochelatase causes abundant protoporphyrin-IX accumulation in colon cancer. FASEB J. 2008; 22:500-509. [PubMed: 17875605]

21. Poloyac SM, Tortorici MA, Przychodzin DI, Reynolds RB, Xie W, Frye RF, Zemaitis MA. The effect of isoniazid on CYP2E1- and CYP4A-mediated hydroxylation of arachidonic acid in the rat liver and kidney. Drug Metab Dispos. 2004; 32:727-733. [PubMed: 15205388]

22. Yue J, Peng RX, Yang J, Kong R, Liu J. CYP2E1 mediated isoniazid-induced hepatotoxicity in rats. Acta Pharmacol Sin. 2004; 25:699-704. [PubMed: 15132840]

23. Chien JY, Thummel KE, Slattery JT. Pharmacokinetic consequences of induction of CYP2E1 by ligand stabilization. Drug Metab Dispos. 1997; 25:1165-1175. [PubMed: 9321520]

24. Singla A, Moons DS, Snider NT, Wagenmaker ER, Jayasundera VB, Omary MB. Oxidative stress, Nrf2 and keratin up-regulation associate with Mallory-Denk body formation in mouse erythropoietic protoporphyria. Hepatology. 2012; 56:322-331. [PubMed: 22334478]

25. Williams M, Van der Zee J, Van Steveninck J. Toxic dark effects of protoporphyrin on the cytochrome P-450 system in rat liver microsomes. Biochem J. 1992; 288(Pt 1):155-159. [PubMed: 1332695]

26. Lyoumi S, Abitbol M, Rainteau D, Karim Z, Bernex F, Oustric V, Millot S, Letteron P, Heming N, Guillmot L, Montagutelli X, Berdeaux G, Gouya L, Poupon R, Deybach JC, Beaumont C, Puy H. Protoporphyrin retention in hepatocytes and Kupffer cells prevents sclerosing cholangitis in erythropoietic protoporphyria mouse model. Gastroenterology. 2011; 141:1509-1519. 1519 e1501-1503. [PubMed: 21762662]

27. Thomas BH, Zeitz W, Whitehouse LW. Effect of rifampin, phenobarbital pretreatment, and acetylator phenotype on acetylisoniazid metabolism in the rabbit. Can J Physiol Pharmacol. 1987; 65:419-423. [PubMed: 3580961] 

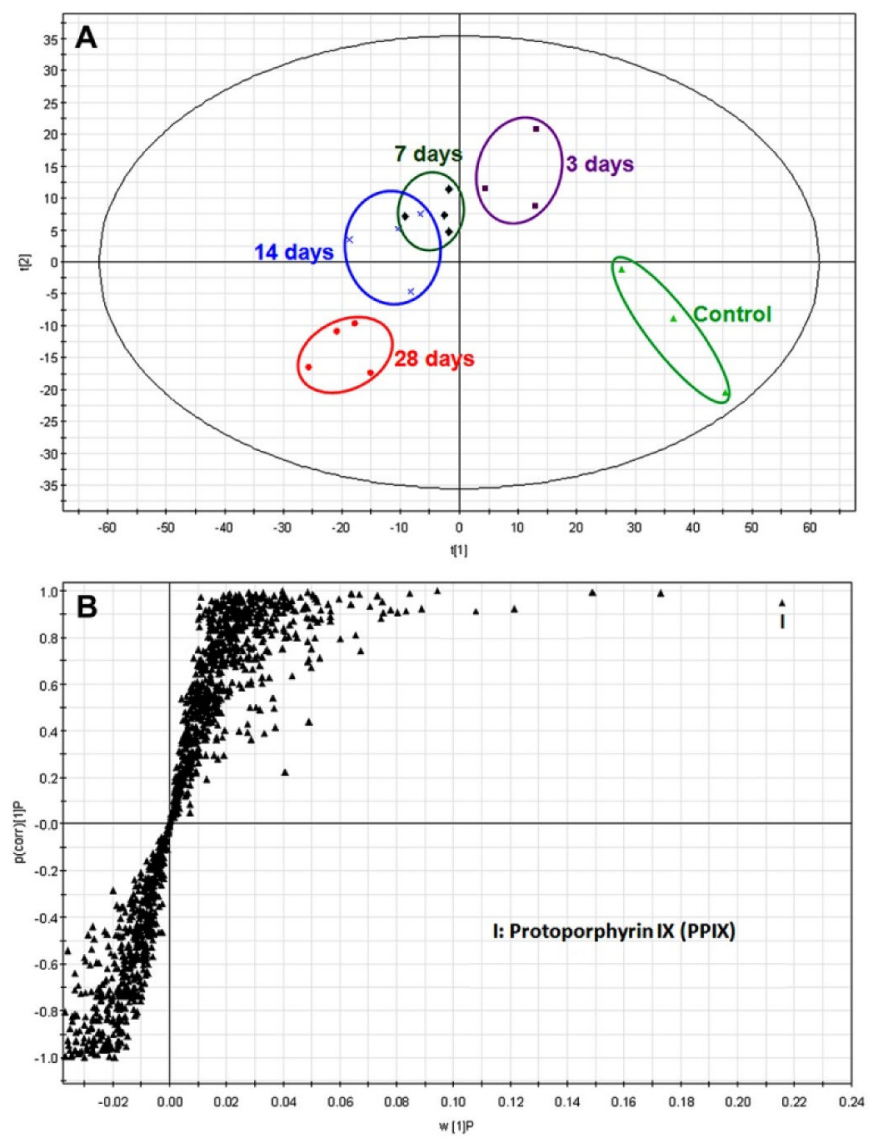

Figure 1. Effect of INH on mouse liver metabolome

The mice were treated with $400 \mathrm{mg} / \mathrm{L}$ INH in drinking water for 0-28 days. Liver samples were analyzed by UPLC-QTOFMS in positive mode. (A) Separation of liver samples from the control and INH-treated mice in a PCA score plot. The $t[1]$ and $t[2]$ values represent the score of each sample in principle component 1 and 2, respectively. (B) Loading S plots of liver samples generated by OPLS-DA. The $x$-axis is a measure of the relative abundance of ions, and the $y$-axis is a measure of the correlation of each ion to the model. The number 1 ranking ion was identified as PPIX. 

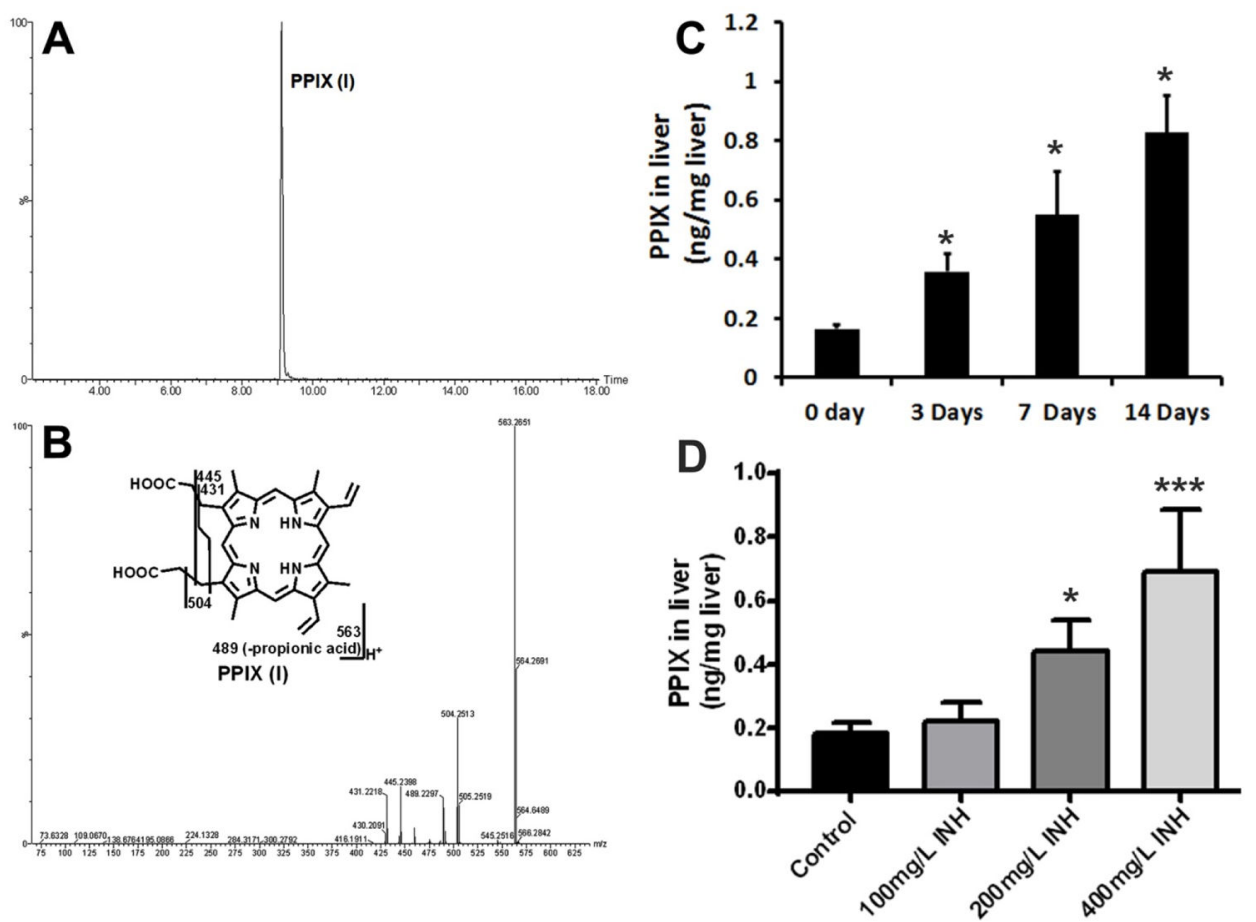

Figure 2. Identification and quantification of PPIX (I)

(A) Extracted chromatogram of PPIX. (B) MS/MS of PPIX. (C) Time-dependent accumulation of PPIX in the liver of mice treated with $400 \mathrm{mg} / \mathrm{L}$ INH in drinking water for 0-14 days. (D) Dose-dependent accumulation of PPIX in the liver of mice treated with 0, 100,200 , or $400 \mathrm{mg} / \mathrm{L} \mathrm{INH}$ in drinking water for 14 days. ${ }^{*} P<0.05$, $* * * P<0.001 \mathrm{vs}$ control $(n=3$ or 4$)$. 

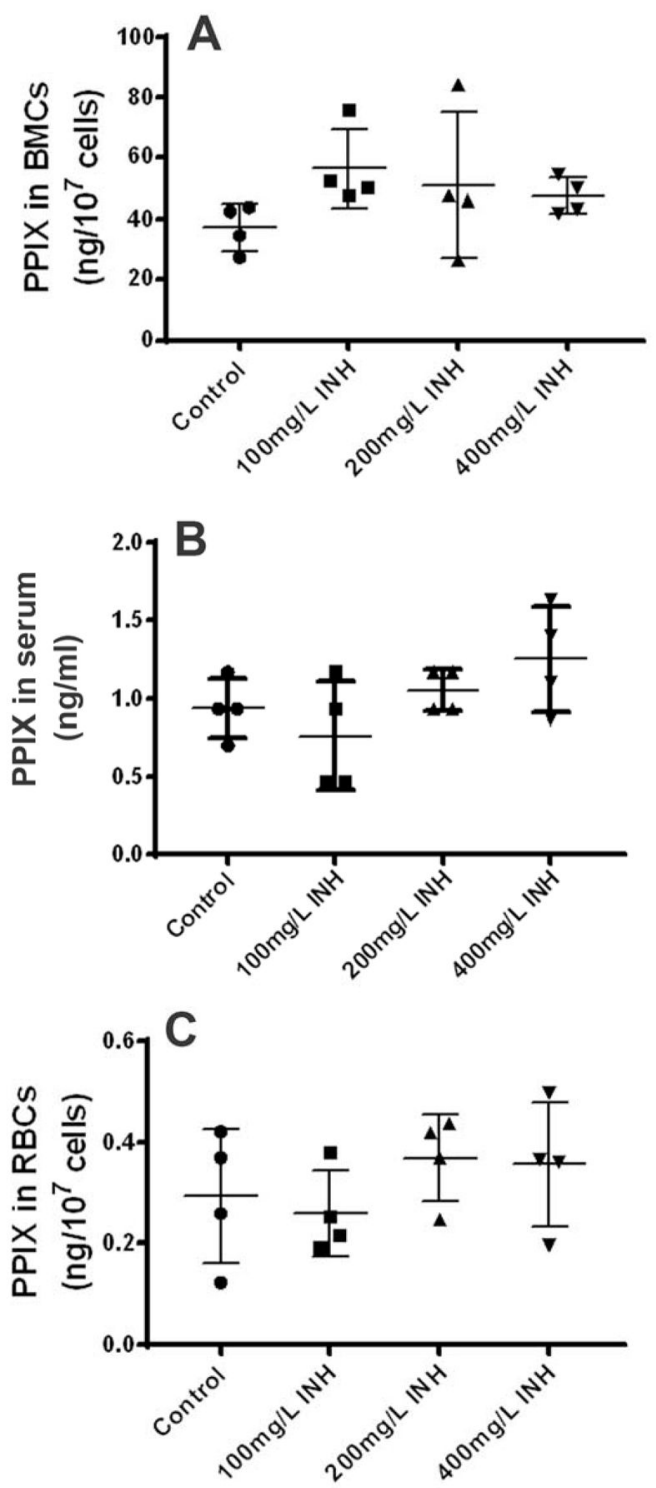

Figure 3. Effect of INH on PPIX levels in bone marrow cells (BMCs), serum and red blood cells (RBCs)

The mice were treated with 0, 100, 200, or $400 \mathrm{mg} / \mathrm{L}$ INH in drinking water for 14 days. All samples were analyzed by UPLC-QTOFMS in positive mode. (A) PPIX in BMCs. (B) PPIX in serum. (C) PPIX in RBCs. All data were expressed as mean $\pm \operatorname{SD}(n=4)$. 

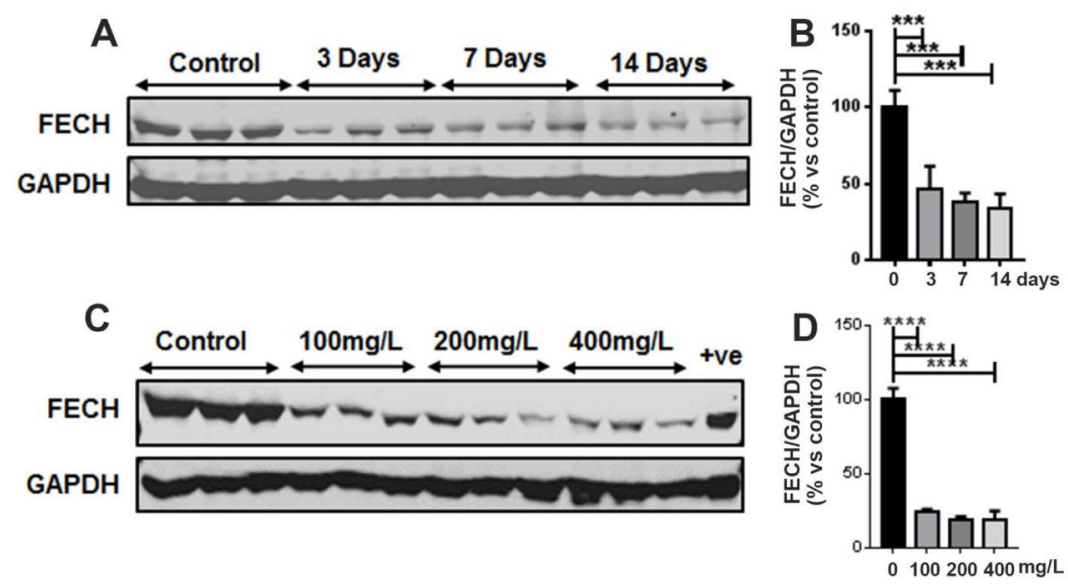

Figure 4. Effect of INH on FECH expression in the liver

FECH protein was analyzed by western blotting. GAPDH was used as loading control. (A and B) FECH expression in the liver of mice treated with $400 \mathrm{mg} / \mathrm{L}$ INH in drinking water for 0-14 days. (C and D) FECH expression in the liver of mice treated with 0, 100, 200 or $400 \mathrm{mg} / \mathrm{L} \mathrm{INH}$ in drinking water for 14 days. All data were expressed as mean \pm SD $(\mathrm{n}=3)$. The data in the control group were set as $100 \%$. *** $P<0.001$, **** $P<0.0001$ vs control. 

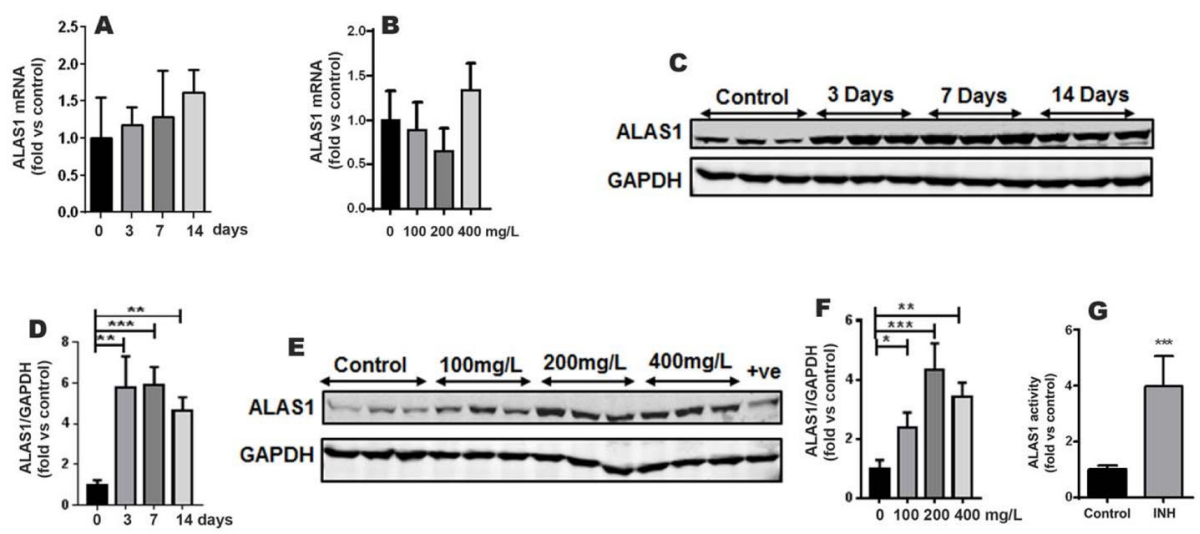

Figure 5. Effect of INH on ALAS1 expression and activity in the liver

ALAS1 mRNA expression were analyzed by qPCR and ALAS1 protein was analyzed by western blotting. GAPDH was used as loading control for western blotting. (A) ALAS1 mRNA expression in the liver of mice treated with $400 \mathrm{mg} / \mathrm{L}$ INH in drinking water for 0-14 days. (B) ALAS1 mRNA expression in the liver of mice treated with 0, 100, 200 and 400 $\mathrm{mg} / \mathrm{L}$ INH in drinking water for 14 days. (C and D) ALAS1 protein expression in the liver of mice treated with $400 \mathrm{mg} / \mathrm{L} \mathrm{INH}$ in drinking water for 0-14 days. (E and F) ALAS1 protein expression in the liver of mice treated with $0,100,200$ or $400 \mathrm{mg} / \mathrm{L}$ INH in drinking water for 14 days. (G) Effect of INH on ALAS1 activity in mouse liver. The mice were treated with vehicle or $400 \mathrm{mg} / \mathrm{L}$ INH in drinking water for 3 days. Liver mitochondria were used for analysis of ALAS1 activity. All data were expressed as mean \pm SD ( $n=3$ or 4$)$. The data in the control group were set as $1 . * P<0.05, * * P<0.01, * * * P<0.001$ vs control. 